\title{
LETRAMENTO NA EDUCAÇÃO DE PESSOA COM SURDEZ: GARANTIA DE APROPRIAÇÃO DA LINGUẢGEM A PARTIR DA PRÁTICA SIGNIFICATIVA DA LÍNGUA
}

NASCIMENTO, Alessandra Pereira ${ }^{1}$

BARBOSA, Maria do Carmo Rodrigues ${ }^{2}$

\begin{abstract}
RESUMO: O presente artigo tem como objetivo discutir a importância do letramento na educação de pessoa com surdez como garantia de apropriação da linguagem a partir da prática significante da língua. Procurou-se neste trabalho enfatizar o letramento como um "ponto de partida" no processo de transmissão de conhecimento e promoção do desenvolvimento cognitivo e social do surdo ressaltando as suas implicações no processo de alfabetização em contrapartida as possibilidades e recursos existentes no processo que facilitam o letramento de alunos com surdez, tornando prazerosa e possível a aprendizagem de forma efetiva e significativa, considerando a situação psicossocial do surdo e, principalmente, sua condição bilíngue e bicultural.
\end{abstract}

Palavras-chave: Alfabetização. Letramento. Linguagem. Surdez.

\section{LITERACY IN EDUCATION OF PERSON WITH DEAFNESS: GUARANTEE OF APPROPRIATION OF THE LANGUAGE FROM THE LANGUAGE PRACTICE MEANINGFUL}

SUMMARY: This article aims to discuss the importance of literacy in education of person with deafness as a guarantee of appropriation of the language from the language practice signifier. It was this work emphasize the literacy as a "starting point" in the process of transmitting knowledge and promotion of social and cognitive development of deaf emphasizing its implications in the process of literacy in contrast possibilities and existing resources in the process that facilitate literacy of pupils with deafness, making enjoyable and possible learning effectively and significant psychosocial, considering the situation of the deaf and condition bilingual and bicultural curriculum.

Keywords: Literacy. Literacy. Language. Deafness.

\section{INTRODUÇÃO}

... Aprender a ler, a escrever, alfabetizar-se é, antes de mais nada, aprender a ler o mundo, compreender o seu contexto, não numa manipulação mecânica de palavras, mas numa relação dinâmica que vincula linguagem e realidade. (Paulo Freire)

No Brasil, a partir do final da década de 1980, muitos autores introduziram ao vocabulário da Educação e das Ciências Linguísticas o termo letramento, cujo conceito vai além da alfabetização ou apropriação da tecnologia da escrita, correspondendo ao uso efetivo dessa tecnologia em práticas sociais que a envolve. Essa prática suscita o questionamento sobre a garantia de apropriação da linguagem a partir

\footnotetext{
${ }^{1}$ Graduada em Letras e Pedagogia e Especialista em Educação Inclusiva. E-mail: alessandra.nascimento09@gmail.com

${ }^{2}$ Orientador, Me em Educação. Docente da Faculdade de Filosofia, Ciências e Letras de Ituverava. E-mail: carmenrodrigues@netsite.com.br
} 
da prática significante da língua e se dá pelo acesso à língua de sinais para as pessoas com surdez dentro de seus limites pessoais e não de padrões impostos pela sociedade, cujo "ponto de partida" é a prática do letramento.

Durante o desenvolvimento desse trabalho deteu-se na busca da análise dos saberes práticos ou os saberes da experiência na prática do letramento no contexto de implementação da política nacional de inclusão, assinalando estratégias de aplicação do alfabetizar e letrar nos espaços educacionais baseando em teorias e fundamentações que mostram as diferentes possibilidades e recursos existentes que facilitam o processo de letramento de alunos com surdez na aquisição da linguagem, ressaltando que a alfabetização/letramento acontece naturalmente através da escrita da língua de sinais, respeitando assim a identidade própria da língua.

\section{PRESSUPOSTOS TEÓRICOS}

Historicamente, a escrita é uma das grandes "invenções" da humanidade, que surge a partir da necessidade do homem de registrar, armazenar dados, enfim, de preservar sua história, sendo um processo de aperfeiçoamento do homem, um enriquecimento exterior, um desenvolvimento intelectual e cultural.

O domínio da língua oral e escrita é fundamental para a participação social efetiva, pois é por meio dele que o homem se comunica, tem acesso as informações, expressa e defende pontos de vista, partilha ou constrói visões de mundo, produz conhecimentos.

Como enfatiza Ferreiro (2001), a língua escrita é um objeto de uso social, com uma existência social e não apenas escolar.

A escrita não é um produto escolar, mas sim um objeto cultural, resultado do esforço coletivo da humanidade. Como objeto cultural, a escrita cumpre diversas funções sociais e tem meios concretos de existência [...] Existem inúmeras amostras de inscrições nos mais variados contextos (letreiros, embalagens, tevê, roupas, periódicos, etc.). (FERREIRO, 2001, p. 43)

Sabe-se da necessidade de pensar a língua escrita a partir da perspectiva do surdo, da visualidade e dos sentidos atribuídos pela sua primeira língua. Fala-se muito da possibilidade visual do surdo, mas é necessário também inseri-lo nesta cultura da imagem, que muitas vezes não lhe faz sentido algum, já que muitas imagens são produzidas por ouvintes, a partir de sua cultura e experiência na linguagem oral.

O letramento possibilita ao aluno com surdez encontrar-se no mundo e com o mundo também a partir da segunda língua: ser tocado por ela, de tal modo que esta língua lhe dê sentido ao que lhe acontece.

Enfatiza Bondia:

O letramento que desejamos é aquele que possibilite ao surdo encontrar-se no mundo e como o mundo também a partir da segunda língua: ser tocado por ela, de tal modo que esta língua lhe dê sentido ao que lhe acontece. (BONDIA, 2002 apud MOURA; VERGAMINI; CAMPOS, 2008)

O problema da construção da escrita em alunos com surdez é um problema bastante constatado por vários estudos, fato esse, que evidencia o fracasso das práticas de alfabetização de alunos com surdez, que na verdade, são as mesmas utilizadas para alunos ouvintes. 
Os alunos com surdez apresentam uma tendência natural ao não aprendizado da língua oral e dificuldades na compreensão de muitas palavras. A alfabetização, processo de ensino da língua oral e escrita através de uma prática estruturada (regras de formação de sílabas, vocábulos, frases) e repetitiva não oferece uma aprendizagem efetiva a estes alunos. Pelo contrário, ressalta a questão da educação de surdos citada por Skliar (2005, p.15): "o ouvitismo, conjunto de representações dos ouvintes, a partir do qual o surdo está obrigado a olhar-se e a narrar-se como se fosse ouvinte", condição desfavorável as suas reais possibilidades.

O letramento vem em direção contrária à alfabetização. Pensar o aluno com surdez como aquele que compreende e interage com o mundo por meio de experiências visuais faz do letramento um processo que proporciona estas experiências.

De acordo com Scribner (1984) o letramento enfatiza valores pragmáticos ou de sobrevivência:

\begin{abstract}
A necessidade de habilidades de letramento na nossa visa diária é óbvia; no emprego, passeando pela cidade, fazendo compras, todos encontramos situações que requerem o uso da leitura ou a produção de símbolos escritos. Não é necessário apresentar justificativas para insistir que as escolas são obrigadas a desenvolver nas crianças as habilidades de letramento que as tornarão aptas a responder a estas demandas sociais cotidianas. (SCRIBNER, 1984 apud SOARES, 2006, p. 73)
\end{abstract}

O letramento se encaixa adequadamente à situação dos surdos. Situação marcada por dificuldades com a escrita, leitura e contextualização. Através do uso de portadores de textos e ilustrações, práticas muito comuns no processo de letramento, fazem com que o contato com a escrita e leitura torne-se agradável e significativa, e assim, o aluno com surdez pode visualizar não só a grafia, mas as imagens que representarão o que todas aquelas letras querem dizer, abrindo caminhos para as interpretações e a amenização das dificuldades com a contextualização apresentadas por estes alunos.

\title{
A PESQUISA
}

A presente pesquisa deu-se através de procedimentos de observação sistemática e aplicação de questionários fechados e atividades livres e contou com a participação de alunos com surdez frequentadores de sala de recursos, professor interprete e instrutor surdo.

Traçado o perfil dos sujeitos de pesquisa notou-se que a idade dos alunos com surdez é sempre superior a média entre etapa de ensino e faixa etária estabelecida pela legislação vigente. Verificou-se que o grau de surdez com a classificação de perda auditiva profunda e severa dá-se com maior ocorrência entre o grupo. Também que todos os alunos utilizam-se como meio de comunicação dominante a Língua Brasileira de Sinais - LIBRAS ${ }^{3}$ com exceção de dois alunos que também oralizam.

Em etapa de análise e discussão dos dados foi possível identificar claramente as convenções que a escrita do aluno com surdez desenvolve quanto a grafia, emprego dos verbos, a elaboração de frases e utilização de pronomes pessoais.

\footnotetext{
${ }^{3}$ LIBRAS é uma das siglas para denominar a Língua Brasileira de Sinais, reconhecida legalmente pela Lei 10.436 de 24/04/2002.
} 
Texto elaborado por Gardênia ${ }^{4}$, um dos sujeito da pesquisa.

\section{QUEM SOU EU?}

Ninha familia um tem sundo umaio en gosto ansigas tem muito bom en gosta aprende coijas libras bom sunda ela convesar amigas Buncar casas gosta ela muito legal en aprende estudo cossas palarias, ibras sempre aprende from. rlew irmão muito luniar cousas muito comesar librar coisas tambion familia lrencian ela liom

Mire amigas tem nome pessoas sundas corsas Elaine, Elir, Lucimana, Gueherme, gilmar, alex, flañi, Ihatriá, maniela, maxia, stefam ela amigas lom.

Mes gato ela dormir com en cama todo, meu rmigar surdas ela muito difúil.

\footnotetext{
${ }^{4}$ Gardênia: 18 anos, estudante da $1^{\text {a }}$ série do Ensino Médio, sempre estudou na rede regular de ensino. Percebe-se que a estudante possui idade superior a média dos alunos da $1^{\mathrm{a}}$ série do Ensino Médio que é de 15 anos. Apresenta grau de surdez profunda, decorrente no período pré-natal, domina a língua de sinais e apresenta dificuldades quanto à contextualização e escrita.
} 
Texto elaborado por $\mathbf{J a s m i n}^{5}$, sujeito da pesquisa.

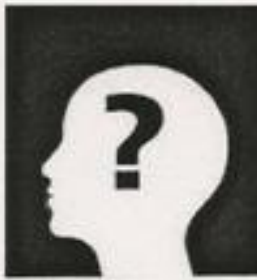

\section{QUEM SOU EU?}

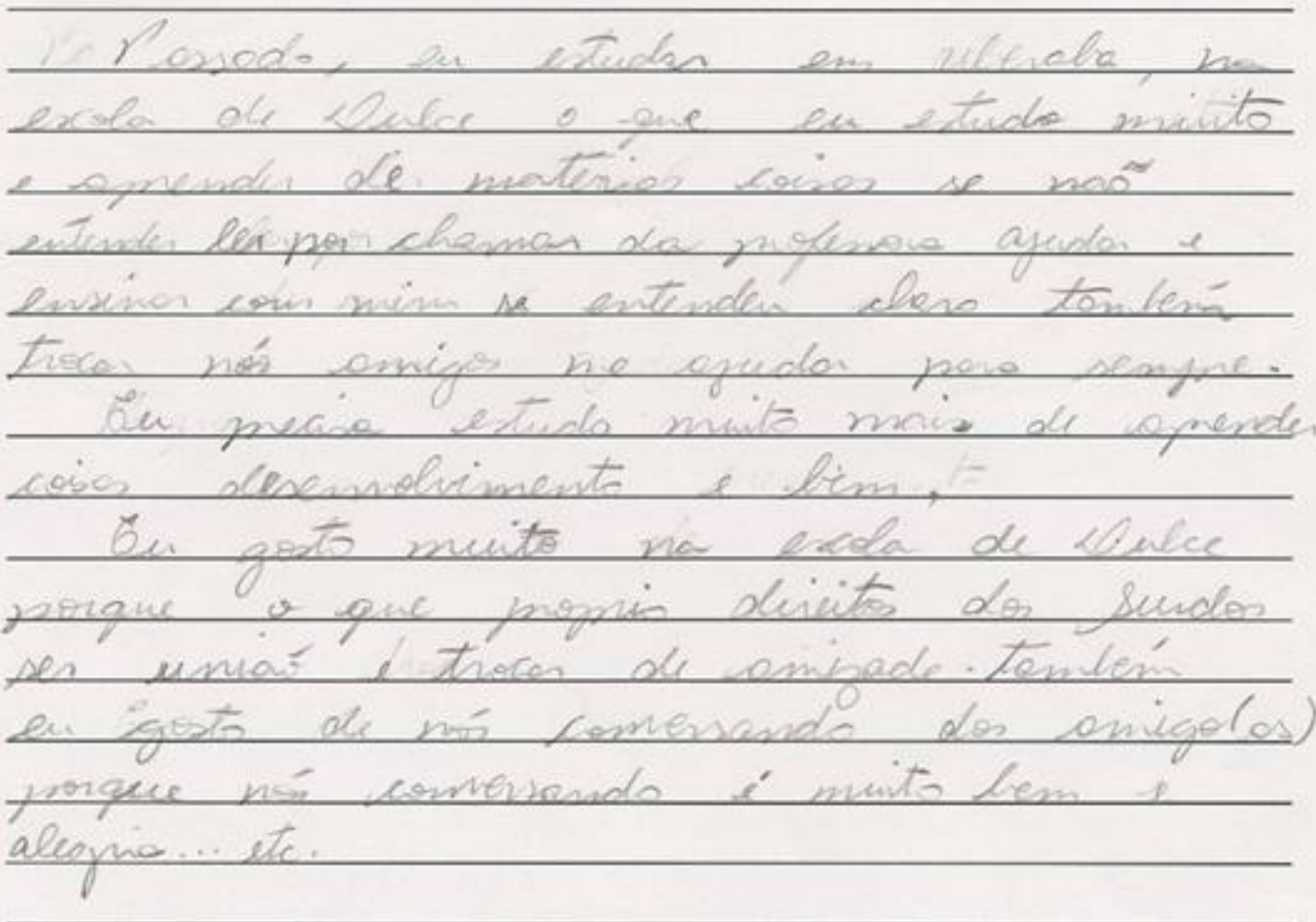

${ }^{5}$ Jasmin: 18 anos, estudante da $6^{\mathrm{a}}$ série do Ensino Fundamental, estudou até a $5^{\mathrm{a}}$ série em escola especial; hoje frequenta escola regular. Nota-se que esta aluna está com idade bem superior à média de idade para a $6^{\text {a }}$ série que é de 12 anos. Apresenta grau de surdez severa, decorrente no período pós-natal, utiliza da língua de sinais como meio de comunicação e apresenta dificuldades com contextualização, escrita e leitura. 


\section{ANÁLISE E DISCUSSÃO DOS DADOS}

Os sujeitos da pesquisa escreveram um texto em impresso apropriado, elaborado pela pesquisadora trilhando os passos de ordenação, classificação e análise de dados, que com o auxílio da professora interprete da sala de recursos apresentou a proposta da atividade às alunas com surdez e pontuou os assuntos a serem abordados. Entre eles: a família, amigos, escola, enfim assuntos ligados ao dia-a-dia de cada uma.

Aplicada a atividade e após uma análise foi possível identificar claramente as convenções que a escrita da pessoa com surdez desenvolve quanto a grafia, emprego dos verbos, a elaboração das frases, a utilização de pronomes pessoais, enfim as pecularidades da língua de sinais.

\section{Recorte 1: Trecho Atividade "Quem sou eu” escrito por Gardênia}

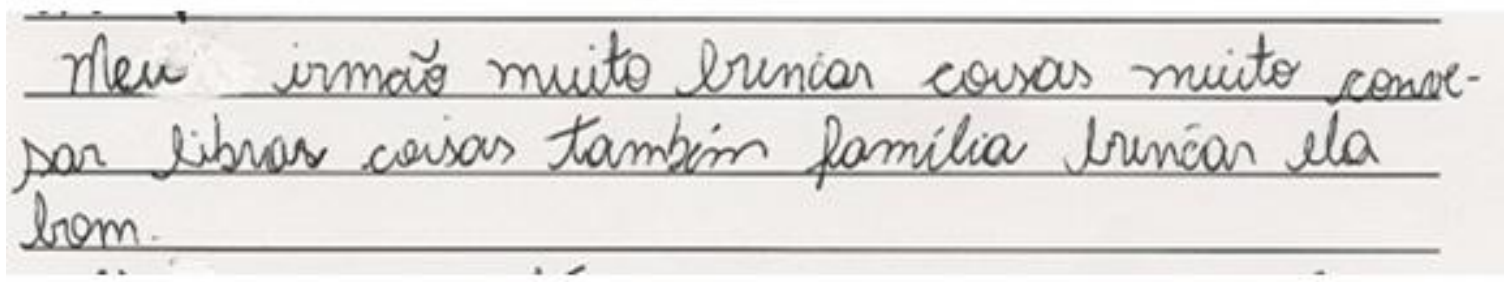

Percebe-se aqui a diferença estrutural da língua de sinais e a dificuldade na escrita quanto à ordenação das ideias e vocabulário.

Segundo as autoras Salles; Faulstich; Carvalho; Ramos (2004, p. 120-122) a escrita do aluno com surdez é peculiar. Não usa artigos, não usa preposições, não faz flexão verbal. Enfim, são singularidades na escrita muito próximas das existentes em textos de estrangeiros que estão aprendendo português.

\section{Recorte 2: Trecho Atividade "Quem sou eu” escrito por Gardênia}

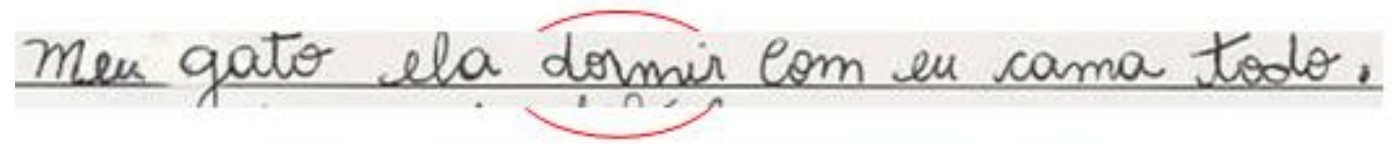

Os verbos são apresentados no infinitivo. Todas as concordâncias e conjugações são feitas no espaço.

\section{Recorte 3: Trecho Atividade "Quem sou eu” escrito por Jasmin}

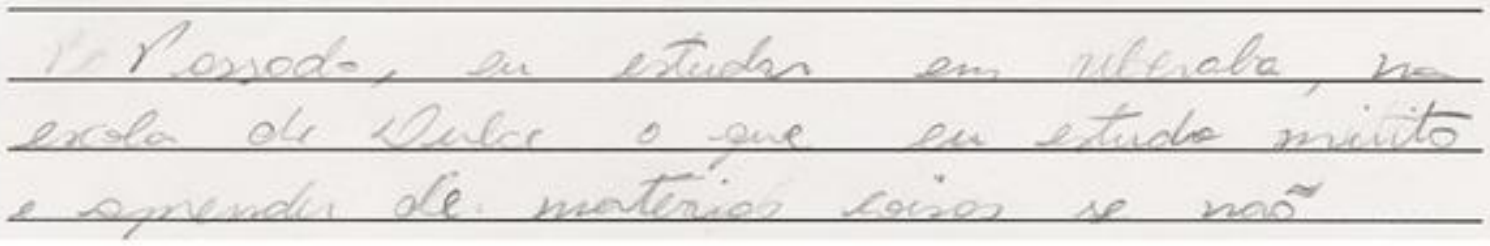




\section{Recorte 4: Trecho Atividade “Quem sou eu” escrito por Jasmin}

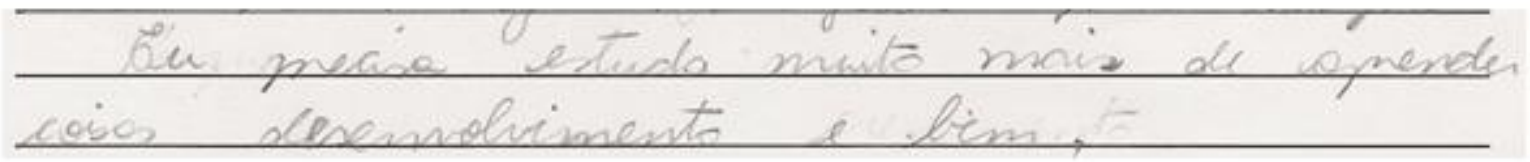

As frases obedecem à estrutura da LIBRAS, e não à do Português.

Os pronomes pessoais são representados pelo sistema de apontuação. Apontar em LIBRAS é culturalmente e gramaticalmente aceito.

Há também a predominância de pronomes de primeira e terceira pessoa, que frequentemente não combinam com o referente ou com a forma flexionada do verbo.

Nota-se que o aluno com surdez precisa se sentir envolvido com o processo de aprendizagem e no caso dos alunos com surdez a língua de sinais é o "fio condutor", o fator mediador entre o aluno com surdez e o conhecimento. Somente por meio da língua que o aluno com surdez constrói sua subjetividade e conquista seu espaço.

\section{CONSIDERAÇÕES FINAIS}

O estudo aqui apresentado não se propôs a resultados definitivos, mas sim a ampliar as discussões em torno da importância do letramento na educação de pessoa com surdez como garantia de apropriação da linguagem a partir da prática significante da língua, tendo como ponto de partida, as possibilidades proporcionadas pelo letramento para que o surdo se desenvolva dentro de seus limites pessoais e não de padrões impostos pela sociedade colocando o acesso à língua de sinais como garantia de apropriação da linguagem a partir da prática significante da língua.

Em síntese, compreende-se que, a alfabetização, processo que reflete a proposta do método fônico, aprendizado da associação entre fonemas e grafemas, é inviável para o surdo, já que este interage e interpreta o mundo através de experiências visuais e não de conhecimentos prévios internalizados pela exploração da oralidade, procedimento adotado na alfabetização.

Diferentemente a aprendizagem pelo letramento ocorre de forma contínua e constante; atemporal, sendo permanente tanto em relação à língua escrita quanto nas linguagens tecnológicas (letramento digital).

Muda a forma de pensar do indivíduo e pode libertá-lo da indiferença e segregação. Sendo a capacidade de comunicação condição fundamental para que a criança surda se desenvolva de maneira segura e de acordo com seu grupo, ouvintes ou não, enfatizando assim a importância fundamental que a educação bilíngue tem para eles.

A alfabetização se ocupa da aquisição da escrita e leitura enquanto o letramento "focaliza os aspectos sócio-históricos da aquisição de um sistema escrito por uma sociedade" (Tfouni, 1995, p. 20), e ainda, "é o estado ou condição de quem não apenas sabe ler e escrever, mas cultiva e exerce as práticas sociais que usam a escrita". (Soares, 2006, p. 47)

Considera-se a prática do letramento um "ponto de partida" (Salles; Faulstich; Carvalho; Ramos, 2004) no processo de transmissão de conhecimento e promoção do desenvolvimento cognitivo e social do surdo, uma garantia de apropriação da linguagem a partir da prática significante da língua. Nesse sentido, o letramento faz uso de estratégias de ensino que levam em consideração a situação psicossocial do surdo e, principalmente, sua condição bilíngue e bicultural. 


\section{REFERÊNCIAS}

BRASIL. Secretaria de Educação Fundamental. Parâmetros curriculares nacionais: introdução aos parâmetros curriculares nacionais/Secretaria de Educação Fundamental. Brasília: MEC/SEF, 1997. 126p.

FERREIRO, E. Reflexões sobre Alfabetização. São Paulo: Cortez, 2001. 104 p.

FREIRE, P. A Importância do Ato de Ler: em três artigos que se completam. São Paulo: Cortez, 2003. $87 \mathrm{p}$.

MOURA, M. C. de; VERGAMINI, S. A. A.; CAMPOS, S. R. L. de (org.). Educação para surdos: práticas e perspectivas. São Paulo: Santos, 2008.

SKLIAR, C. (Org.). A surdez um olhar sobre as diferenças. 3 ed. Porto Alegre: Mediação, 2005.

SOARES, M. Letramento: um tema em três gêneros. 2 ed. Belo Horizonte: Autêntica, 2006, 125 p.

SOARES, M. Letramento e Alfabetização: as muitas facetas. Revista Brasileira de Educação, Minas Gerais, n. 25, p. 5-17, jan./fev./mar./abr./ 2004.

TFOUNI, L.V. Letramento e alfabetização. São Paulo: Cortez, 1995. 